\title{
Drugs used in prostatic enlargement and lower urinary tract symptoms: unseen and overlooked effects on sexual health
}

\author{
Ashrafuzzaman $\mathrm{SM}^{\mathrm{a}}$, Rahim $\mathrm{MA}^{\mathrm{b}}$, Latif $\mathrm{ZA}^{\mathrm{c}}$
}

\begin{abstract}
Benign prostatic hyperplasia (BPH) is one of the most common genitourinary complications in men over 50 years of age and typically presents with lower urinary tract symptoms (LUTS) and may need medical and occasionally surgical interventions. Few of them may only need advice on behavioral modification like less water intake after sunset, avoid tea, coffee after evening, avoid alcohol and less use of diuretics. The symptoms related to BPH or LUTS without any prostatic enlargement are incomplete voiding, frequency, intermittency, urgency, weak stream, straining and nocturia. For most patients with mild to moderate symptoms of BPH [International Prostate Symptom Score (IPSS) <8 or 8-19 respectively] monotherapy with an á-1-adrenergic antagonist remains initial treatment. The choice of specific á-adrenergic antagonist agent is generally based on cost and side effect profile. Other classes of medications include 5á-reductase inhibitors and phosphodiesterase (PDE) 5 inhibitors. In men who have mild to moderate symptoms of BPH and concomitant erectile dysfunction (ED), PDE-5 inhibitors are reasonable alternative. Now a days á-1-adrenoceptor blockers and 5á-reductase inhibitors are often combined to give a synergistic effect. A review of the current literature identified several adverse sexual side effects, including ED, decreased libido, orgasmic disorders and ejaculatory disorders. It is important to know the extent of these side effects, as the clinician and patient will need to decide the cost of improved voiding symptoms. The prime adverse effect is ejaculatory disorders including the absence of ejaculation. Clinical consideration for BPH/LUTS should include the elements of male sexual function, patient's age and the characteristics and comprehensive effects of each group of drugs. Methodological bias in clinical studies, such as the subjective evaluation of the sexual side effect makes it difficult to determine the ideal drug for treatment. Men without ED or irritant symptoms who desire medical therapy but cannot tolerate á-1-adrenergic antagonists and do not have predominately irritant symptoms or concomitant ED, treatment with a 5á-reductase inhibitor is a reasonable. Treatment for 6 to 12 months is generally needed before prostate size is sufficiently reduced to improve symptoms. Symptoms are usually reversible, so drugs may need to be continued for long time or indefinitely under supervision of specialist.
\end{abstract}

Key words: adverse effects, benign prostatic hyperplasia, lower urinary tract symptoms, sexual health.

(BIRDEM Med J 2019; 9(1): 240-247)

\footnotetext{
Author information

a. SM Ashrafuzzaman, Professor \& Head, Endocrinology, BIRDEM General Hospital, Dhaka, Bangladesh.

b. Muhammad Abdur Rahim, Associate Professor, Nephrology, BIRDEM General Hospital, Dhaka, Bangladesh.

c. Zafar Ahmed Latif, Professor, Endocrinology, BIRDEM General Hospital, Dhaka, Bangladesh.

Address of correspondence: SM Ashrafuzzaman, Professor \& Head, Endocrinology, BIRDEM General Hospital, Dhaka, Bangladesh. Email: ashrafzaman1961@gmail.com

Received: December 13, 2018

Accepted: August 29, 2019
}

\section{Introduction}

Benign prostatic hyperplasia $(\mathrm{BPH})$ is a clinical syndrome which includes prostate enlargement and lower urinary tract symptoms (LUTS). The aim of BPH treatment is alleviating urination problems, preventing prostatic disease progression and improving the quality of life. Over the past two decades, the standard of treatment has largely shifted from surgery to drug therapy. A greater understanding of detrusor physiology as well as the development of effective drugs for solving the dynamic and static components of the obstruction 
in the prostate and bladder neck have paved the path for the ubiquity of pharmacological therapy for BPH. However, clinical studies in the 1990s reported that despite the amelioration of LUTS, adverse effects of BPH drug therapy began to surface. ${ }^{1}$ These effects were noted as sexual dysfunction, which can be divided into erectile dysfunction (ED), ejaculatory dysfunction (EjD), orgasmic disorders as well as sexual desire disorders.

Pharmacological BPH therapy protocols advocate the use of á-blockers (ABs) and 5á-reductase inhibitors (5ARI) individually or in combination, as well as phosphodiesterase-5 (PDE5) inhibitors, individually or concomitantly with ABs (Table I). Adverse sexual side effects can occur as a result of the drug group itself or specific drugs within the group. ${ }^{1}$ Watchful waiting is usually utilized in patients with an American Urological Association (AUA) symptom score $<10$. ABs bind to $a_{1}$-adrenoceptors and act by relaxing the smooth muscles of the prostate and bladder neck to improve urine flow and facilitate urination. They do not reduce prostatic volume or curb the natural progression of BPH. Nonetheless, ABs do vary in uroselectivity and the production of adverse effects. ${ }^{2}$ They can be nonselective (e.g., doxazosin, terazosin and alfuzosin) and selective (e.g., tamsulosin and silodosin). 5ARIs cause the inhibition of 5á-reductase enzymes and prevent the conversion of non-active forms testosterone to dihydro testosterone (DHT), the androgen steroid compound mainly responsible for the initial and subsequent enlargement of the prostate gland. ${ }^{3}$ The enzyme has two isoforms: type 1 (found in the liver and skin) and type 2 (found in reproductive tissues). 5ARIs are prominently available as finasteride and dutasteride with both exhibiting similar clinical effects. 5ARIs may lead to ED and decreased libido compared to placebo. ${ }^{4}$ The combination of $\mathrm{AB}$ and $5 \mathrm{ARI}$ is an increasingly popular mode of treatment which incorporates the combined effect of both components including combined sexual side effects. Lastly, PDE5 inhibitors (e.g., tadalafil) are commonly used in order to treat ED as well as inhibit phosphodiesterase 11, which is found in the prostate and testes. As of yet, PDE11 inhibition with therapeutic doses of tadalafil has shown no clinical significance. ${ }^{5}$ Nonetheless, findings from studies have revealed that PDE5 is highly expressed in the lower urinary tract and supporting vasculature and that PDE5 inhibition potentially decreases smooth muscle cell proliferation in the prostate, relaxes smooth muscle in the prostate, bladder neck and supporting vasculature, increases blood perfusion to the lower urinary tract and modulates bladder afferent nerve activity. ${ }^{6}$ For these reasons, in 2011, the Food and Drug Administration (FDA) approved tadalafil to treat the signs and symptoms of $\mathrm{BPH}$ as well as a combination of BPH and ED when the conditions coincide.

Table I Medications to treat LUTS attributed to $\mathrm{BPH}$

\begin{tabular}{|c|c|c|}
\hline Drug class & & Medication \\
\hline \multirow[t]{4}{*}{ Alpha 1 blockers (ABs) } & . & Tamsulosin \\
\hline & . & Terazocin \\
\hline & . & Alfuzocin \\
\hline & . & Silodocin \\
\hline \multirow[t]{2}{*}{ 5á-reductase inhibitors (5ARIs) } & . & Finasteride \\
\hline & . & Dutasteride \\
\hline \multirow[t]{4}{*}{ Anticholinergic drugs } & . & Oxybutynine \\
\hline & . & Darifenacin \\
\hline & . & Tolterodine \\
\hline & . & Solfenacin \\
\hline Beta-3 adrenergic agonist & . & Mirabegron \\
\hline Phosphodiesterase-5 & . & Sildenafil \\
\hline \multirow[t]{3}{*}{ inhibitors (PDE5i) } & . & Tadalafil \\
\hline & . & Avanafil \\
\hline & . & Verdenafil \\
\hline
\end{tabular}

[UpToDate 2018 online]

Management of sexual dysfunction in men treated with BPH/LUTS should be focused and symptom-dependent. A validated questionnaire of enquiry, such as the international index of erectile function or male sexual health questionnaire, should be used to assess sexual function before beginning pharmacological therapy for BPH/LUTS. The clinician then must assess comorbidities and concomitant medications, particularly those that affect erectile capacity as well as address any risk factors for cardiovascular disease before initiating 
any sort of therapy. Also, before pharmacological therapy, the physician must advise the patient on lifestyle modifications to improve sexual function, such as weight loss and an appropriate exercise regimen. The physician may even consider PDE5 inhibitors if necessary, especially if the patient presents with symptoms of ED. If the patient has $\mathrm{EjD}$, he must be advised to transform his BPH/LUTS therapy to an alternative AB or 5ARI. Once the relevant sexual dysfunction is present, the physician must provide the counseling on the safety and tolerability of pharmacological therapies for BPH/ LUTS. Follow up can be done in $4-8$ weeks to check sexual function, after which 6-month checkups are adequate. $^{7}$

\section{Adverse sexual side effects of selected medications Alpha $(\alpha)$ blockers (ABs)}

AB monotherapy was the second most common treatment regimen employed for $\mathrm{BPH} .{ }^{8}$ Blockage of the $a_{1}$-adrenergic receptors in the prostate and bladder neck causes smooth muscle relaxation and improves urinary flow. ${ }^{9}$ Three types of $\alpha_{1}$-adrenergic receptors are present throughout the body including $\alpha_{1 \mathrm{~A}}, \alpha_{1 \mathrm{~B}}$, and $\alpha_{1 \mathrm{D}}{ }^{9}$. The majority (70\%) of the á ${ }_{1}$-adrenergic receptors in the prostate are of the $\alpha_{1 \mathrm{~A}}$ subtype. ${ }^{9}$

Tamsulosin: Tamsulosin is a third generation pharmacologically uroselective antagonist of $\alpha_{1 A^{-}}$ adrenoceptors in the prostate with minimal affinity for the $\alpha_{1 \mathrm{~B}}$-adrenoceptors of cardiovascular smooth muscle, thus not establishing any risk for hypotension. ${ }^{10}$ Tamsulosin has been reported to affect libido, erectile function and ejaculation. Priapism has rarely been reported since market approval and is expected to occur in less than 1 in 50,000 patients. ${ }^{11}$ In one study that analyzed the results of the male sexual function-4 (MSF-4) questionnaire found that of 354 men treated with tamsulosin, $40.7 \%$ considered their sexual function as deteriorated after 6 months of therapy. ${ }^{12}$ A decrease in libido was reported by $1.0 \%$ of men receiving the 0.4 mg dose of tamsulosin and $2.0 \%$ of men receiving the $0.8 \mathrm{mg}$ dose of tamsulosin. ${ }^{10}$ These percentages are in comparison to a $1.2 \%$ incidence of decreased libido occurring in patients receiving placebo. ${ }^{9}$ The results of the MSF-4 questionnaire also revealed that ejaculation disorders were the most frequently reported side effect of tamsulosin therapy. ${ }^{12}$ Abnormal ejaculation including ejaculation failure, ejaculation disorder and retrograde ejaculation were reported in approximately $8.4 \%$ of men receiving the $0.4 \mathrm{mg}$ dosage of tamsulosin and $18.1 \%$ of men receiving the $0.8 \mathrm{mg}$ dose of tamsulosin. ${ }^{9}$ These percentages are much higher than that of the placebo group, which was $0.2 \% .^{9}$ These frequencies suggest a dose-related effect of tamsulosin on ejaculatory function.

Alfuzosin: Alfuzosin is a clinically uroselective á $_{1}$ adrenergic receptor antagonist. ${ }^{13}$ As per the prescribing information, adverse event data was obtained from three placebo-controlled clinical trials that were conducted over a 3-month time period and involved 1,608 men, 473 of whom received one alfuzosin $10 \mathrm{mg}$ extendedrelease tablet daily while the remaining 1,135 received $15 \mathrm{mg}$ daily. ${ }^{13}$ Impotence was reported to occur in between $0 \%$ and $3 \%$ of patients receiving alfuzosin and not significantly more frequently than with placebo (between $0 \%$ and $1 \%$ ), based on clinical trials results. ${ }^{14}$ Decrease in erectile function based on a metaanalysis of randomized controlled and open label trials has been reported to be between $0.0 \%$ and $2.8 \%$ in patients receiving alfuzosin. ${ }^{15}$ In comparison, the patients receiving a placebo in these trials reported decreases in erectile function at rates ranging from 0 $2.3 \%{ }^{15}$ A meta-analysis of randomized controlled trials including a total of 1,302 patients demonstrated incidences of decreased sexual desire in $0-0.7 \%$ of patients receiving alfuzosin and $0.7 \%$ of patients receiving the placebo. Priapism was reported after market approval, so incidence was not reported for this adverse effect. ${ }^{13}$ The reported incidence of ejaculatory disorders with the use of alfuzosin is generally less than $1.5 \%$ based on information from clinical trials. ${ }^{7,15}$ This percentage is in comparison to $0 \%$ of patients in the placebo groups reporting such adverse effects. ${ }^{15}$ No dose-effect relationship was observed with alfuzosin and the incidence of sexual side effects. ${ }^{16}$

Interestingly, data from a preliminary open-label study of 3,076 men with LUTS or BPH had shown that the use of alfuzosin $10 \mathrm{mg}$ daily for one year had resulted in improvements from baseline in ED and ejaculatory disorders ( $\mathrm{P}<0.001$ for both conditions). ${ }^{17}$ The mean improvements from baseline in these two conditions were greater for men with more severe LUTS and BPH at baseline than men with milder symptoms. Further, alfuzosin is well tolerated when used in combination with low doses of PDE5 inhibitors for ED ${ }^{14} \mathrm{~A}$ six- 
month open label study conducted in 42 men demonstrated that the side effect profile of alfuzosin in combination with tadalafil was similar to that with each agent alone. ${ }^{18}$

It has been assumed by many researchers and healthcare providers that the ED caused by ABs was due to retrograde ejaculation. Previously mentioned study in rats also demonstrated that tamsulosin had a significantly greater inhibitory effect on bladder neck closure and seminal vesicle contractions than alfuzosin. ${ }^{19}$ A study of 17 Korean urologists demonstrated that treatment with tamsulosin 0.2 and $0.4 \mathrm{mg}$ once daily significantly decreased mean ejaculate volume. ${ }^{20,21}$ Tamsulosin also causes anejaculation in $35 \%$ of participants while anejaculation was not observed in any of the participants in the alfuzosin or placebo group.

\section{$5 \alpha$-reductase inhibitors (ARI)}

Dutasteride: Dutasteride is a competitive 5ARI that antagonizes both isoforms of $5 \alpha$-reductase. ${ }^{22}$ Dutasteride is indicated alone or in combination with the $\alpha_{1 \mathrm{~A}}$-adrenergic receptor antagonist tamsulosin for the treatment of men with an enlarged prostate with symptomatic BPH, for symptom improvement, reduction in risk of acute urinary retention (AUR) and reduction in risk for BPH-related surgery. In patients with severe symptoms of BPH (IPSS $\geq 20$ ), those who are known to have a large prostate $(>40 \mathrm{~mL})$ and/or in those who do not get an adequate response to maximal dose monotherapy with an $\alpha$-adrenergic antagonist, combination treatment with an $\alpha$-adrenergic antagonist and a 5 - $\alpha$-reductase inhibitor is usually given. Based on the package insert, common adverse reactions from clinical trials [ARIA 3001, ARIA 3002 (both United States) and ARIA 3003 (19 countries)] in 4,325 men, 2,167 receiving dutasteride were found to have impotence, decrease in libido, breast enlargement/ tenderness and EjD. ${ }^{22,23}$ In the combination trial with tamsulosin (CombAT trial), these adverse events occurred more frequently in the combination therapy group with than either monotherapy alone. ${ }^{22}$ Although ED was the number one cause of treatment discontinuation in all study arms, discontinuation rates were low at only $1-1.5 \%$.

Finasteride: Finasteride, another 5ARI, selectively inhibits $5 \alpha$-reductase type 2 , found predominantly in the prostate gland. ${ }^{24,25}$ Finasteride is indicated alone for the treatment of symptomatic BPH for symptom improvement, reduction in risk of AUR and reduction in need for surgery, as well as in combination with the $a_{1}$-selective antagonist doxazosin, together indicated to slow the progression of symptomatic BPH. Finasteride is taken once daily without regard to meals with or without doxazosin. Like dutasteride, finasteride also has the following contraindications: hypersensitivity, pregnancy, women of childbearing age, and pediatrics. ${ }^{24}$

In clinical trials, the adverse effects reported were mainly related to sexual function and included impotence, decreased libido, decrease ejaculate volume, EjD and breast enlargement/tenderness. However, findings of studies may vary based on set up and criteria. A 2015 study found reduced ejaculation strength and orgasmic function but no significant decrease in sexual desire, which is usually a notorious side effect of 5ARIs. ${ }^{26} \mathrm{~A} 5$-year prospective analysis by Kaplan et al. found that the incidence of $\mathrm{ED}$, $\mathrm{EjD}$ and reduced libido were higher with dutasteride $(5.1 \%$, $2.4 \%$ and $2.7 \%$ respectively) compared to finasteride use $(2.1 \%, 1.8 \%$ and $1.4 \%$ respectively) despite their equality in effectively treating LUTS. ${ }^{27}$

Combined therapy of $\mathrm{ABs}$ and 5á-reductase inhibitors

In a 2015 study, complete absence of ejaculation was experienced by $23 \%$ of patients on combined therapy, but only $15 \%$ on tamsulosin and $5 \%$ on finasteride. ${ }^{26} \mathrm{In}$ the same study, it was found that erection improved in all three treatment groups. Patients with severe urinary symptoms often identified relief in the act of urination with improved erectile function.

\section{Anticholinergics}

For patients with LUTS related to over active bladder $(\mathrm{OAB})$, the primary goal is to decrease involuntary detrusor contractions. Normal bladder contractions are primarily triggered by the neurotransmitter acetylcholine. Tolterodine, oxybutynin, darifenacin, solifenacin, fesoterodine and trospium are approved in the United States for OAB and in placebo-controlled trials have been shown to reduce the sensation of urgency, decrease episodes of frequency and urgency, incontinence and increase voided volume. The anticholinergic tertiary amines including darifenacin and solifenacin are selective M3 receptor antagonist. Selective M3 blockade theoretically may decrease peripheral side effects. ${ }^{14-17}$ Trospium is a quaternary amine and is classified as a smooth muscle relaxant with some anticholinergic effects. It has limited ability to cross the blood-brain barrier and may have less impact on cognitive dysfunction. ${ }^{18,19}$ 


\section{Phosphodiesterase-5 inhibitors}

Tadalafil: A study conducted by Hellstrom et al. states that tadalafil does not induce any detrimental effects on spermatogenesis or testicular function. ${ }^{28}$ Tadalafil is commonly prescribed for men with ED along with LUTS secondary to $\mathrm{BPH} .{ }^{29}$ McVary and McKenna reported a multicenter, randomized, double-blind placebocontrolled study involving 281 men reported to have LUTS secondary to BPH were randomly assigned to once daily $5 \mathrm{mg}$ tadalafil for 6 weeks, proceeded by an increase in dosage to $20 \mathrm{mg}$ for 6 weeks ( 12 weeks of placebo) and found that there were decreases in IPSS in regards to a mean change from baseline to 6 weeks of " 2.8 with tadalafil $5 \mathrm{mg}$ compared to " 1.2 with the placebo $(\mathrm{P}<0.003)$ and " 3.8 at 12 weeks with tadalafil $5 / 20 \mathrm{mg}$ compared to " 1.7 with the placebo $(\mathrm{P}<0.001) .{ }^{30} \mathrm{~A}$ similar study by Roehrborn et al. was conducted using a larger sample size of men with LUTS secondary to BPH and 2.5, 5, 10 and $20 \mathrm{mg}$ of tadalafil were used. ${ }^{30}$ An improvement of baseline to endpoint after 12 weeks, IPSS mean change was reported to be "3.9 of $2.5 \mathrm{mg}$ of tadalafil $(\mathrm{P}<0.015)$, " 4.9 for $5 \mathrm{mg}$ of tadalafil ( $\mathrm{P}<0.001)$, "5.2 for $10 \mathrm{mg}$ of tadalafil and "5.2 for $20 \mathrm{mg}$ of tadalafil $(\mathrm{P}<0.001)$, compared to " 2.3 for the placebo. ${ }^{30}$ Another study showed a small but statistically significant median maximum urinary flow rate improvement for tadalafil versus placebo. ${ }^{31}$ In fact, a 2015 clinical study observed improvement in approximately two-thirds of their patients, with over $50 \%$ reporting after 1 week of therapy and more than $70 \%$ after 4 weeks. ${ }^{32}$ No unexpected adverse events have been reported; no meaningful adverse effects have been observed in visual, auditory or cardiovascular systems. Tadalafil is also effective in men of different ages, disease severity, prior $\mathrm{AB}$ exposure and prostatic volumes. ${ }^{33}$ The noted changes in IPSS may have been induced by an increased concentration of the cGMP resulting in a decrease of prostate muscle tension. ${ }^{6}$ The effects of nitric oxide (NO) on the smooth muscle of the bladder and the inhibition of PDE in the prostate and the prostatic urethra is documented but not well studied. ${ }^{34}$ Though the current literature lacks an explicit description of the effect of tadalafil on the prostate, bladder, penis and LUTS proposed mechanisms for how tadalafil may ameliorate BPH-associated LUTS include: upregulating $\mathrm{NO} /$ cyclic guanosine monophosphate activity (for decreasing smooth muscle tension in the prostatic stroma and capsule and attenuating cellular proliferation associated with prostate/bladder hypertrophy), downregulating Rho-kinase and endothelin-1 activity (for increasing smooth muscle relaxation to decrease bladder outlet obstruction and restore erection), modulating autonomic hyperactivity and afferent nerve activity, reducing inflammation, as well as increasing pelvic perfusion and reducing ischemia (to reverse pelvic organ atherosclerosis). ${ }^{7,35}$

Administering tadalafil concomitantly with $\mathrm{ABs}$ has been reported to increase hypotension or orthostatic hypotension. ${ }^{36}$ The PDE5-inhibiting mechanism of tadalafil is similar to that of ABs in regards to peripheral vasodilation. In a study by Kloner et al., the additive effects of tadalafil on two commonly prescribed ABs, doxazosin and tamsulosin, were compared. ${ }^{37}$ The hypotensive effects of doxazosin were increased by 10 $\mathrm{mmHg}$, while there was no significant change when tamsulosin was taken with tadalafil. ${ }^{37}$ This hypotensive effect may diminish the ability to produce or maintain an erection. Kloner et al. determined that tamsulosin is a safe $\mathrm{AB}$ when combined with tadalafil. ${ }^{37}$ When concurrently administrating other ABs with tadalafil, a great deal of precaution must be taken. An alternative management approach is combining tadalafil with finasteride; a 2015 study found the combination therapy had clinically meaningful improvement in symptoms, great treatment satisfaction and no report of adverse side effects. ${ }^{38}$ This combination therapy is well-tolerated regardless of the presence/absence of ED at treatment initiation. ${ }^{39}$

Due to the fact that sexual dysfunction occurs around the same age as BPH symptoms in most men, it is difficult to definitively determine the degree to which different medications used in the treatment of BPH contribute to some symptoms of sexual dysfunction. ${ }^{12}$ Further, it appears to be difficult to predict which patients will experience sexual dysfunction as a result of the use of medications for BPH. Studies that attempted to identify correlation between patient characteristics such as age and prostatic volume have failed to find any associations. Direct comparative trials of the various agents used for the treatment of BPH would also be helpful in order to provide more definitive conclusions regarding which agents pose the lowest risk of causing sexual side effects, particularly impotence and decreased libido. Incidence rates of adverse sexual side effects have found to be higher at year 1 of follow-up compared to thereafter for finasteride and the finasteride-doxazosin combination ${ }^{40}$ suggesting that the effects early in the course of treatment may later subside. This would be an important precaution for the physician to address to the patient. Also noteworthy is that, adverse effects may be linked to comorbidities typically tied to BPH patients. ${ }^{40}$ Adverse sexual side effects of selected ABs and 5ARIs have been summarized in table II. 
Table II á ${ }_{1}$-adrenergic antagonists, 5á-reductase inhibitors and their associated adverse sexual side effects (Except GI, CV and CNS side-effects).

\begin{tabular}{|c|c|}
\hline Drug & Adverse sexual side effects \\
\hline Tamsulosin & $\begin{array}{l}\text { Decrease in libido; decrease in erectile function; adverse effects in ejaculation; priapism; } \\
\text { deterioration in sexual function }(2-10 \%)\end{array}$ \\
\hline Alfuzosin & Impotence; decrease in erectile function; priapism $(1-2 \%)$ \\
\hline Silodosin & Retrograde ejaculation; dry orgasm $(\sim 1 \%)$ \\
\hline Dutasteride & $\begin{array}{l}\text { Impotence; decrease in libido; breast enlargement; breast tenderness; ejaculation disorders (8- } \\
10 \%)\end{array}$ \\
\hline Finasteride & $\begin{array}{l}\text { Impotence; decreased libido; decrease ejaculate volume; ejaculation disorder; breast } \\
\text { enlargement; breast tenderness }\end{array}$ \\
\hline Tolterodine & Decreased libido, erectile dysfunction $(2-10 \%)$ \\
\hline
\end{tabular}

\section{International prostate symptom score 9 (I-PSS):}

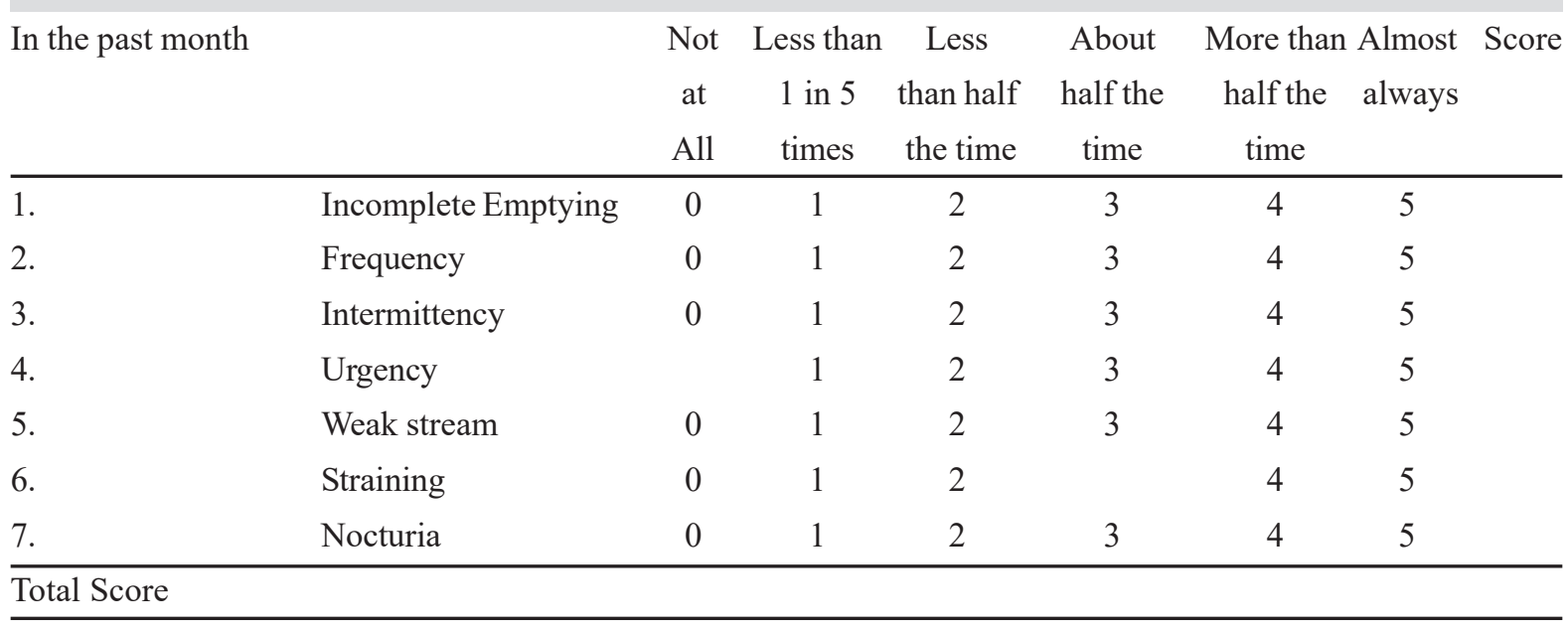

SCORE: 1-7: MILD

Score: 8-19: MODERATE

Score: 20-35: SEVERE

\section{Conclusion}

Many patients who present to their healthcare provider with LUTS due to BPH will also have ED or EjD and vice versa. Although á-adrenergic receptor blockers and 5-á-reductase inhibitors are highly effective in treating $\mathrm{BPH}$-associated LUTS, these agents have sexual adverse effects that cause many men to discontinue therapy. The discovery of nitric oxide as a major factor in the mechanism of erection has led to the development of new drugs for ED, including PDE inhibitors. Preliminary data support the theory that inhibition of PDE isoenzymes in the prostate may improve LUTS due to $\mathrm{BPH}$ through relaxation of prostatic smooth muscle. Further studies of PDE inhibitors in men with ED and BPH-associated LUTS are indicated. LUTS in men have most often been attributed to bladder outlet obstruction (BOO) resulting from benign prostatic enlargement (BPE) or BPH. Before the pharmacological therapy for $\mathrm{BPH}$ is initiated, it is crucial that the physician discusses potential side effects with the patient so they can comprehend the risks. Patients with significant symptoms and findings consistent with BPH and BOO as cause for LUTS may be treated empirically. Urological referral is needed who are less than 45 years old or who do not respond to empiric therapy. Medical treatment for $\mathrm{BPH}$ and $\mathrm{BOO}$ includes $\mathrm{ABs}$, PDE5 
inhibitors, 5ARIs or a combination. Men with urgency symptoms and no evidence of a significantly elevated PVR be treated with an anticholinergic. Men with symptoms of $\mathrm{OAB}$ and $\mathrm{BOO}$ be treated with a combination therapy of an anticholinergic plus an alpha blocker. In some cases, patients may prefer to continue treatment with ABs or 5ARIs regardless of experiencing the sexual side effects. Other options available would be either to decrease the dosage of medication, decrease the frequency or terminate the treatment completely and instead opt for surgery. Based on the patient's presentation of LUTS and possible sexual dysfunction, the physician may evaluate an alternative class of BPH therapy drugs. The effect of $\mathrm{AB}$ on libido and erectile function is similar to that of a placebo, while having different effects on ejaculation. 5ARIs produce sexual side effects and increased risk for ED, EjD and decreased libido compared to a placebo. Combination therapy with $\mathrm{AB}$ and $5 \mathrm{ARI}$ triples the risk for $\mathrm{EjD}$ incidence compared to that of $\mathrm{AB}$ or $5 \mathrm{ARI}$ used individually. The PDEI, tadalafil is presently a new treatment alternative to other established drugs for LUTS, such as the aforementioned ABs or 5ARIs. However, it is not just an alternative, since sexual adverse events associated with ABs and 5ARIs are unavoidable; tadalafil is the only drug that can treat both ED and LUTS simultaneously. Nevertheless, objective improvement on LUTS has been met with controversy. many of this depends on physician choice and experience.

Conflicts of interest: Nothing to declare.

\section{References}

1. Gandhi J, Weissbart SJ, Smith NL, Kaplan SA, Dagur G, Zumbo A, et al. The impact and management of sexual dysfunction secondary to pharmacological therapy of benign prostatic hyperplasia. Transl Androl Urol 2017; 6(2):295-304.

2. Deters LA, Costabile RA, Moore CR, Patel VR. What are the potential adverse effects of alphablockers in the treatment of BHP? Med Scape (updated on Jan 15, 2019)

3. Hamilton RJ, Andriole GL, Freedland SJ. 5á-reductase inhibitors: preventing the treatable. Eur Urol 2012;62:24245 .

4. Nickel JC, Gilling P, Tammela TL, Morrill B, Wilson TH, Rittmaster RS. Comparison of dutasteride and finasteride for treating benign prostatic hyperplasia: the Enlarged Prostate International Comparator Study (EPICS). BJU Int 2011;108:388-94.
5. Briganti A, Salonia A, Gallina A, Saccà A, Montorsi P, Rigatti $\mathrm{P}$, et al. Drug Insight: oral phosphodiesterase type 5 inhibitors for erectile dysfunction. Nat Clin Pract Urol 2005;2:239-47.

6. Coward RM, Carson CC. Tadalafil in the treatment of erectile dysfunction. Ther Clin Risk Manag 2008;4:1315-30.

7. Yokoyama O, Igawa Y, Takeda M, Yamaguchi T, Murakami M, Viktrupetal L. Tadalafil for lower urinary tract symptoms secondary to benign prostatic hyperplasia: a review of clinical data in Asian men and an update on the mechanism of action. Ther Adv Urol 2015;7:249-64.

8. Mirone V, Sessa A, Giuliano F, Berges R, Kirby M, Moncada I. Current benign prostatic hyperplasia treatment: impact on sexual function and management of related sexual adverse events. Int J Clin Pract 2011;65:1005-13.

9. Seftel A, Rosen R, Kuritzky L. Physician perceptions of sexual dysfunction related to benign prostatic hyperplasia (BPH) symptoms and sexual side effects related to BPH medications. Int J Impot Res 2007;19:386-92.

10. Henkel R, Bastiaan HS, Schuller S, Hoppe I, Starker W, Menkveld R. Leucocytes and intrinsic ROS production may be factors compromising sperm chromatin condensation status. Andrologia 2010;42:69-75.

11. Song SH, Son H, Kim KT, Kim SW, Moon du G, Moon KH, et al. Effect of tamsulosin on ejaculatory function in BPH/ LUTS. Asian J Androl 2011;13:846-50.

12. Martin DJ, Lluel P, Guillot E, Coste A, Jammes D, Angel I. Comparative alpha-1 adrenoceptor subtype selectivity and functional uroselectivity of alpha-1 adrenoceptor antagonists. J Pharmacol Exp Ther 1997;282:228-35.

13. Zlotta AR, Teillac P, Raynaud JP, Schulman CC. Evaluation of male sexual function in patients with Lower Urinary Tract Symptoms (LUTS) associated with Benign Prostatic Hyperplasia (BPH) treated with a phytotherapeutic agent (Permixon), Tamsulosin or Finasteride. Eur Urol 2005;48:269-76.

14. van Dijk MM, de la Rosette JJ, Michel MC. Effects of alpha(1)-adrenoceptor antagonists on male sexual function. Drugs 2006;66:287-301.

15. Hellstrom WJ, Sikka SC. Effects of acute treatment with tamsulosin versus alfuzosin on ejaculatory function in normal volunteers. J Urol 2006;176:1529-33.

16. Hisasue S, Furuya R, Itoh N, Kobayashi K, Furuya S, Tsukamoto T. Ejaculatory disorder caused by alpha-1 adrenoceptor antagonists is not retrograde ejaculation but a loss of seminal emission. Int J Urol 2006;13:1311-6.

17. Chapple CR, Baert L, Thind P, Höfner K, Khoe GS, Spångberg A. Tamsulosin $0.4 \mathrm{mg}$ once daily: tolerability in older and younger patients with lower urinary tract symptoms suggestive of benign prostatic obstruction (symptomatic BPH). The European Tamsulosin Study Group. Eur Urol 1997;32: 462-70. 
18. Stojanoviæ N, Ignjatoviæ I, Djeniæ N, Bogdanoviæ D. Adverse Effects of Pharmacological Therapy of Benign Prostatic Hyperplasia on Sexual Function in Men. Srp Arh Celok Lek 2015;143:284-9.

19. Uroxatral package insert [online]. Available

20. McGuire, EJ, Savastano, JA. Effect of alpha adrenergic blockade and anticholinergic agents on the decentralized primate bladder. Neurourol Urodyn 1985; 4:139.

21. Chapple CR, Rechberger T, Al-Shukri S, Meffan P, Everaert $\mathrm{K}$, Huang M, et al. Randomized, double-blind placebo- and tolterodine-controlled trial of the once-daily antimuscarinic agent solifenacin in patients with symptomatic overactive bladder. BJU Int 2004; 93:303.

22. Gupta SK, Sathyan G. Pharmacokinetics of an oral once-aday controlled-release oxybutynin formulation compared with immediate-release oxybutynin. J Clin Pharmacol 1999; 39:289.

23. MacDiarmid SA, Ellsworth PI, Ginsberg DA, Oefelein MG, Sussman DO. Safety and efficacy of once-daily trospium chloride extended-release in male patients with overactive bladder. Urology 2011; 77:24.

24. Staskin DR. Trospium chloride: Distinct among other anticholinergic agents available for the treatment of overactive bladder. Urol Clin North Am 2006; 33:465.

25. Madhuvrata P, Cody JD, Ellis G, Herbison GP, Hay-Smith EJ. Which anticholinergic drug for overactive bladder symptoms in adults. Cochrane Database Syst Rev 2012; 1:CD005429.

26. Hellstrom WJ, Overstreet JW, Yu A, Saikali K, Shen W, Beasley CM Jr, et al. Tadalafil has no detrimental effect on human spermatogenesis or reproductive hormones. J Urol 2003;170:887-91

27. McVary KT, McKenna KE. The relationship between erectile dysfunction and lower urinary tract symptoms: epidemiological, clinical, and basic science evidence. Curr Urol Rep 2004;5:251-7.

28. Roehrborn CG, McVary KT, Elion-Mboussa A, Viktrup L. Tadalafil administered once daily for lower urinary tract symptoms secondary to benign prostatic hyperplasia: a dose finding study. J Urol 2008;180:1228-34.

29. Roehrborn CG, Chapple C, Oelke M, Cox D, Esler A, Viktrup L. Effects of tadalafil once daily on maximum urinary flow rate in men with lower urinary tract symptoms suggestive of benign prostatic hyperplasia. J Urol 2014;191:1045-50.

30. Oelke M, Shinghal R, Sontag A, Baygani SK, Donatucci CF. Time to onset of clinically meaningful improvement with tadalafil $5 \mathrm{mg}$ once daily for lower urinary tract symptoms secondary to benign prostatic hyperplasia: analysis of data pooled from 4 pivotal, double-blind, placebo controlled studies. J Urol 2015;193:1581-9.

31. Nishizawa O, Yoshida M, Takeda M, Yokoyama O, Morisaki Y, Murakami M, et al. Tadalafil $5 \mathrm{mg}$ once daily for the treatment of Asian men with lower urinary tract symptoms secondary to benign prostatic hyperplasia: analyses of data pooled from three randomized, double-blind, placebocontrolled studies. Int J Urol 2015;22:378-84.

32. Uckert S, Kuthe A, Jonas U, Stief CG. Characterization and functional relevance of cyclic nucleotide phosphodiesterase isoenzymes of the human prostate. J Urol 2001;166:248490.

33. Hatzimouratidis K. A review of the use of tadalafil in the treatment of benign prostatic hyperplasia in men with and without erectile dysfunction. Ther Adv Urol 2014;6:135-47.

34. Kloner RA, Mitchell M, Emmick JT. Cardiovascular effects of tadalafil in patients on common antihypertensive therapies. Am J Cardiol 2003;92:47M-57M.

35. Kloner RA, Jackson G, Emmick JT, Mitchell MI, Bedding A, Warner MR, et al. Interaction between the phosphodiesterase 5 inhibitor, tadalafil and 2 alpha-blockers, doxazosin and tamsulosin in healthy normotensive men. J Urol 2004; 172:1935-40.

36. Roehrborn CG, Casabe A, Glina S, Sorsaburu S, Henneges C, Viktrup L. Treatment satisfaction and clinically meaningful symptom improvement in men with lower urinary tract symptoms and prostatic enlargement secondary to benign prostatic hyperplasia: Secondary results from a 6-month, randomized, double-blind study comparing finasteride plus tadalafil with finasteride plus placebo. Int J Urol 2015;22:582 7.

37. Glina S, Roehrborn CG, Esen A, Plekhanov A, Sorsaburu S, Henneges $C$, et al. Sexual function in men with lower urinary tract symptoms and prostatic enlargement secondary to benign prostatic hyperplasia: results of a 6-month, randomized, double-blind, placebo-controlled study of tadalafil coadministered with finasteride. J Sex Med 2015;12:12938.

38. Kaplan SA, Lee JY, Meehan AG, Kusek JW. Time Course of Incident Adverse Experiences Associated with Doxazosin, Finasteride and Combination Therapy in Men with Benign Prostatic Hyperplasia: The MTOPS Trial. J Urol 2016;195:1825-9.

39. La Torre A, Giupponi G, Duffy D, Conca A, Cai T, Scardigli A. Sexual Dysfunction Related to Drugs: a Critical Review. Part V: alpha-Blocker and 5-ARI Drugs. Pharmacopsychiatry 2016;49:3-13. 